\title{
Replacement Model for Street Lighting Systems
}

\author{
A. M. Usman*, Y. A. Adediran, A. O. Otuoze, O. O. Mohammed, O. S. \\ Zakariyya
}

Department of Electrical and Electronics Engineering, Faculty of Engineering and Technology, University of Ilorin, P.M.B 1515 Ilorin, Kwara State, NIGERIA.

\begin{abstract}
Replacing failed bulbs of streetlights in a location can be very tasking and expensive if the optimal time for replacement is not determined. In this paper, a model has been developed that helps to establish the optimal time for the replacement of streetlight bulbs. Burnt-out bulbs are replaced individually when they fail, and group replacement is carried out on all bulbs after a specified time. The costs for both individual replacement and group replacement are determined. The developed model was applied to locally sourced data from a field survey of a streetlight installation at the University of Ilorin, Ilorin, North-central Nigeria. The model gave the optimum replacement time of burnt-out bulbs as the eighteenth week when applied to the data used in this work. The optimum replacement time will be dependent on the dataset used. This makes the developed model useful in establishing the optimal replacement time of any stochastically failing items that are in large quantities. The model will help to reduce maintenance costs for facility managers.
\end{abstract}

Keywords: replacement model, streetlights, burnt-out bulbs, optimum replacement time

\section{INTRODUCTION}

The safety of people and properties of citizens is one of the major responsibilities of the government. One way to achieve this important goal is by ensuring that the entire cities and towns are well illuminated at night. This will help in preventing accidents and enhancing the safety of people and properties. Replacing failed bulbs in street lighting system can be tasking and expensive if an optimal time for replacement is not known. Streetlight is a light source often installed along the road, tunnels, parking lots amongst other places. It is to provide illumination at dusk for road users - drivers and pedestrians as well as providing illumination during rain and fog because of poor visibility. It has remained one of the major attributes of urban and sub-urban settlement since the nineteenth century [1-3]. It operates approximately 4000 hours/year [4], typically 12 hours daily (dusk to dawn). Studies have shown that streetlights have improved traffic and pedestrian safety $[1,3,5,6]$ by reducing the risks of accidents, reduction in rates of crime, and adding to city glamour [7] as well as improving the economic activities [8] among other benefits. The

\footnotetext{
* Corresponding author (Tel: +234 (0)703 7807964$)$

Email addresses: usman.am@unilorin.edu.ng (A. M. Usman), yinusaade2012@gmail.com (Y. A. Adediran), otuoze.ao@unilorin.edu.ng (A. O. Otuoze), reacholaabdul@gmail.com (O. O. Mohammed), sikiruzakariyya@gmail.com (O. S. Zakariyya)
}

streetlight luminaries' systems can be mounted on steel, wooden, or concrete poles [4]. They are fed through either underground cables or overhead, emanating from the nearest available electricity distribution source, depending on the type of pole used in an installation [4].

Despite its obvious advantages, there have been concerns about its impacts on carbon emissions under the Climate Change Act 2008 and the high cost of maintenance [1, 3, 9]. These issues raised are being addressed by various research works, not only by engineer's teams but also by social scientists. The importance of street lighting system has not been subjective but its effects concerning the environment, cost of maintenance, and carbon reduction have been debated recently. Murray and Feng [7] sought out a way to mitigate the negative impact associated with street lighting, with a specific focus on distribution using spatial analytics including geographic information system (GIS) and spatial optimization. This work was able to enhance the spatial distribution efficacy of infrastructure besides providing a chance to ensure that crucial standards are retained. The environmental impact factor of street lighting system is also of concern. The high-intensitydischarge (HID) has remained largely used for street lighting systems [10] until recently when there is now an increase in the use of Light Emitting Diode (LED) lamps due to the need to conserve energy, cost, and environmental impact factors [11]. LED produces light with higher efficacy 
(more lumens per watt) compare to other light sources [12]. Different life cycle analyses (LCA) carried out by $[10,11,13]$ have shown that LED technology has a lower environmental impact factor and conserves more energy compared to the HID technology.

The energy usage of a typical street lighting system can be huge since the streetlights remain lit during operational hours (about 12 hours daily). In the United States, for instance, about $22 \%$ of electricity generation is used on lighting applications, street lighting takes a significant portion of this [12]. In another study, the street lighting system is reported to be consuming $40 \%$ of the total available energy in cities [14]. This is a huge strain on the limited available energy in a country like Nigeria [15] with a population of about 190 million [16] but with $7000 \mathrm{MW}$ of power generation [17]. It is essential to optimally utilize the limited available power for such a large population. There are initiatives to reduce streetlights power consumption as seen in the work of Bilam et al. [18], and Sei et al. [19] where cost-effective and energy-saving methods were proposed.

Like every equipment or machine, the streetlight also requires maintenance. Generally, there are two kinds of maintenance actions in the street lighting system: preventive maintenance (PM) and corrective maintenance (CM) [20]. PM deals with the replacement of installed items after a scheduled time and CM is the replacement of failed items. Previous literature has shown that the implementation of PM on stochastically failing items can help to extend their life span and reduce operating cost [21]. The PM is not exclusive to the replacement of failed bulbs after a scheduled period. It also involves the implementation of other measures such a traditional physical inspections and automated control systems for remote monitoring and management that can lead to a reduction in power consumption, maintenance, and running cost [14, 22-24]. The failures of bulbs are stochastic, which often results in uneven illumination of the area of coverage of a streetlight installation. This study develops a suitable model for replacing burnt-out bulbs of street lighting system to ensure constant and proper illumination in the entire planned area of coverage. In doing so, this study proposes a model that will give the minimum cost for the replacement of burntout bulbs of streetlight over a period by ensuring that no area is entirely put into darkness before replacement is done. The remainder of this paper is organized as follows. In Section 2, the data collection and model development are presented while results and discussion are presented in Section 3. The conclusion of the paper outcome is presented in Section 4.

\section{DATA COLLECTION AND MODEL DEVEL- OPMENT}

There are different types of models in replacement theory. Such models include individual replacement model, repair limits replacement model, routine replacement model, age replacement model, and group replacement theory [20, $25,26]$. Several research works have been dedicated to solving replacement issues based on several policies [21, 25, 27]. Liu [25] described three categories of group replacement; these are:

I T-age group replacement model: in this type of model, no failed item is fixed or replaced in a machine until a planned time $\mathrm{T}$; at this stage, every failed item is replaced concurrently.

II M-failure group replacement model: the overall idea is that repair or replacement is not done on any failed item until a certain number $\mathrm{M}$ of the installed items has failed; then, all failed items are repaired at the same time.

III Group replacement model $(\boldsymbol{m}, \boldsymbol{T})$ : in this model repair or replacement of failed items will take place at a scheduled time $\mathrm{T}$ or when $\mathrm{m}$-number of items have failed in the machine, whichever occurs first.

This work adopts the use of a group replacement model which gives the optimum time of replacement with respect to the cost of burnt-out bulbs without keeping the environment in darkness. The major items in street lighting system are bulbs, chokes, and lamp-holder and they do fail stochastically without any prior notice. Replacing these stochastically failing items simultaneously at a scheduled time will be cheaper compared to replacing every item as it fails. However, waiting until a scheduled time when group replacement would be carried can lead to some parts being covered by the street lighting installation to be in darkness. Therefore, there is a need to balance this and find the best time for replacement to take place.

\subsection{Group Replacement at Discrete Times}

This work applies $(m, T)$ replacement policy to derive a model for replacing street lighting system. Determination of the cost of preventive replacement of the entire street lighting bulbs and the cost of replacing just a bulb is therefore a necessity. The time to failure of a bulb before the mean life is stochastic. Therefore, the replacement decision is to replace a bulb when it fails and to carry out a preventive replacement of all the bulbs after some time. The problem to solve is to determine the discrete-time at which group replacement should be carried out, which is the optimum replacement time.

\subsection{Data Collection}

The streetlight installation of a road at the University of Ilorin, Ilorin, North Central region of Nigeria was used for data collection. In the surveyed installation, all bulbs (from the same manufacturer) were changed the same day. This is to enable us to closely monitor the rate of failure over a period. Somebody is checking and keeping 
records of all the installed bulbs daily to know the number of bulbs that burn out (this is the operator that puts ON/OFF the streetlight daily).

\subsection{Assumptions}

The following assumptions were made in the development of the model:

a. Whenever any bulb fails, it can be because of:

- burnt bulb, or

- Failed choke, or

- An electrical fault in the system.

The most frequent cause of failure in streetlight is burnt bulb. Therefore, our model considers only the cost of replacing the bulb, particularly since a burnt bulb is not repairable.

b. Let the cost of replacing a bulb that fails be represented by $C_{f}$.

c. The time to failure of a bulb is stochastic; that is, a bulb may have a nominal lifetime of 1000 hours (as designed by the manufacturer) but it may fail after working for just 50 hours. The failure of a bulb depends on a lot of operating and environmental factors such as supply voltage, temperature, humidity, etc. Therefore, the failure probability of bulbs in a specified area must be determined by closely observing the number of failures in a week. The number of failures during time $t$ is represented by $F_{(t)}$.

d. It is assumed that all the bulbs are replaced whenever group replacement is to be carried out, irrespective of whether some were individually recently changed. Hence, the cost of carrying out the entire group replacement is also considered. Let the cost of replacing all the bulbs be $C_{p}$.

e. Let the total cost of replacement over a period be $C_{t}$.

\subsection{The mathematical Model}

The replacement decision is to carry out group replacement after $t$ weeks, irrespective of the time when the last PM occurred. The total cost of replacement $C_{t}$ is to be determined. This will include individual replacement cost and group replacement cost, and then the average will be taken. If the optimal cost is to be determined, the cost of replacing all the bulbs is considered every week, as well as the cost of carrying out group replacement after a time $t$ week. The week at which the cost is minimum will be the optimal time for the entire bulb to be replaced. Therefore, the total average cost (TAC) of group replacement by the end of period $t$ is $X_{t}$.

Group replacement cost at time $t$ : The total group replacement cost after time $t$ is given as:

$$
C_{(t)}=C_{p}+C_{f} \sum_{x=1}^{t-1} F(x)
$$

where $F$ is the number of failed bulbs, $C_{p}$ is the cost of replacing the items as a group, and $C_{f} \sum_{x=1}^{t-1} F(x)$ is the cost of replacing the individual failures up to time $t-1$ periods before the group is replaced again.

The cost average for each unit time is:

$$
\frac{C_{(t)}}{t}=\frac{C_{p}}{t}+\frac{C_{f}}{t} \sum_{x=1}^{t-1} F(x)
$$

For optimal replacement period $t$, the value of cost average for each unit time in Eq. (2), must be the minimum. The prerequisite for a minimum of $C_{(t)} / t$ is:

$$
\Delta\left\{\frac{C_{(t)}}{t-1}\right\}<0<\Delta \frac{C_{(t)}}{t}
$$

where

$$
\Delta\left\{\frac{C_{(t)}}{t}\right\}=\Delta \frac{C_{(t+1)}}{t+1}-\frac{C_{(t)}}{t}>0
$$

From Eq. (2), we have

$$
\begin{array}{r}
\frac{C_{(t+1)}}{t+1}-\frac{C_{(t)}}{t} \\
=C_{p}\left(\frac{1}{t+1}-\frac{1}{t}\right)+C_{f} \sum_{x=1}^{t-1} F(x)\left(\frac{1}{t+1}-\frac{1}{t}\right)+\frac{C_{f} F_{(t)}}{t} \\
=\frac{-C_{p}-C_{f} \sum_{x=1}^{t-1} F(x)+t C_{f} F_{(t)}}{t(t+1)}
\end{array}
$$

Therefore, for

$$
\frac{C_{(t+1)}}{t+1}-\frac{C_{(t)}}{t}>0
$$

it is necessary that:

$$
\begin{gathered}
t . C_{f} F_{(t)}>C_{p}+C_{f} \sum_{x=1}^{t-1} F(x) \\
C_{f} F_{(t)}>\frac{C_{f} \sum_{x=1}^{t-1} F(x)}{t}
\end{gathered}
$$

Similarly, for

$$
\Delta\left\{\frac{C_{(t)}}{t}\right\}=\Delta \frac{C_{(t+1)}}{t+1}-\frac{C_{(t)}}{t}>0
$$

the following condition can be derived

$$
C_{f} F_{(t+1)}>\frac{C_{f} \sum_{x=1}^{t-2} F(x)}{t-1}
$$

The inequalities in Eq. (4) and (5) describe the necessary condition for optimal group replacement. In Eq. (4), the expression:

$$
\frac{C_{p}+C_{f} \sum_{x=1}^{t-1} F(x)}{t}
$$


Table 1: Weekly failure probabilities.

\begin{tabular}{lcccc}
\hline $\begin{array}{l}\text { Description of the } \\
\text { surveyed area }\end{array}$ & $\begin{array}{c}\text { No of the bulb } \\
\text { points }\end{array}$ & Bulb type & Rated Voltage & $\begin{array}{c}\text { Average Life Span } \\
\text { of a bulb }\end{array}$ \\
\hline $\begin{array}{l}\text { Block1 to Works Department Road } \\
\text { Faculty of BSS to Faculty of Law }\end{array}$ & 52 & HPS 250 W Bulbs & $220-240 \mathrm{~V}$ & $\begin{array}{c}32 \text { weeks at 12 hours } \\
\text { of operation per day }\end{array}$ \\
\hline
\end{tabular}

represents the cost average for each time if all items are replaced at the end of time $t$, whereas expression $C_{f} F_{(t)}$ represents the cost for the $t$-th period if group replacement is not made at the end of time $t$. Therefore, the TAC $X_{t}$ of group replacement as well as individual replacement as the bulbs fail is

$$
X_{t}=\frac{C_{p}+C_{f} F_{t}}{t}
$$

where $F_{(t)}$ is the number of failures in week $t$.

The number of failed bulbs in a week can be determined using the illustration below.

In a typical streetlight system, assume 1000 bulbs are installed and the bulbs are assumed to have an average/maximum life span of 5 weeks with the following failure probabilities of the total initial installed bulbs shown in Table 2 .

Table 2: Weekly failure probabilities.

\begin{tabular}{lccccc}
\hline Week & $\mathbf{1}$ & $\mathbf{2}$ & $\mathbf{3}$ & $\mathbf{4}$ & $\mathbf{5}$ \\
\hline Failure probability & 0.10 & 0.15 & 0.25 & 0.20 & 0.30 \\
\hline
\end{tabular}

In week 1 with a failure probability of 0.10 of initially installed bulbs (1000), the number of failed bulbs at the end of week 1 is $1000 \times 0.10=100$ bulbs.

From the above illustration, an equation is derived on how to calculate the number of failed bulbs in any week.

Let $N_{t}=$ the total number of installed bulbs in the system.

Let $f_{1}, f_{2}, f_{3} \ldots f_{n}$ be the number of failures in week 1 , week 2 , week 3 , ...week $n$ respectively and $p_{1}, p_{2}, p_{3} \ldots p_{n}$ be the probability of failures in week 1 , week 2 , week $3, \ldots$ week $n$ respectively.

Then, $F_{(t)}=f_{1}+f_{2}+f_{3}+\ldots+f_{n}$

The number of bulbs that failed at the end of week 1 ,

$$
f_{1}=N_{t} \times p_{1}
$$

The number of bulbs that failed at the end of week 2 ,

$$
f_{2}=N_{t} \times p_{2}+f_{1} \times p_{1}=p_{2} N_{t}+p_{1} f_{1}
$$

The number of bulbs that failed at the end of week 3 ,

$$
f_{3}=N_{t} \times p_{3}+f_{1} \times p_{2}+f_{2} \times p_{1}=p_{3} N_{t}+p_{2} f_{1}+p_{1} f_{2}
$$

Equations (7), (8), and (9) lead to the following general equation for calculating the number of bulbs that failed in a week.

$$
F_{(t)}=N_{t} p_{t}+\sum_{x=1}^{t-1} p_{(t-x)} f_{x}
$$

where $F_{t}$ is the number of failures in week $t$.

\subsection{Model Testing and Analysis}

A field data collection and analysis were carried out. This was done at the University of Ilorin. Bulbs of selected streetlights were replaced the same day. Table 1 shows the information in the surveyed area.

Estimated Cost of Corrective Replacement of a Single Bulb that Fails:

A $250 \mathrm{~W}$ bulb costs $\$ 450$

Labour per day at $\$ 2,500$ per worker/labourer $\times 3$ persons $=$ 7,500

Total $=$ ₹7,950 (Seven Thousand, Nine Hundred and Fifty Naira Only)

Estimated Cost of Preventive Replacement of all the Installed Bulbs:

$250 \mathrm{~W}$ bulb: $450 \times 102$ No of bulbs $=\$ 45,900$

Hydraulic platform lorry: $\$ 30,000 \times 1$ day $=$ 丹30,000

Worker/Labourer per day at $\$ 2,500$ per Labour $\times 3$ persons $=\$ 7,500 \times 1$ day $=\$ 7,500$

Total = 83,400 (Eighty-Three Thousand Four Hundred Naira).

\subsection{Failure Probability}

The failure probability is obtained from the data collected from the field survey. There were 102 bulbs in the surveyed area. All the bulbs were replaced in the fourth week of February. The number of bulbs that failed per week were recorded from the first week of March to last week in October. Once a bulb failed, attention was no longer given to it till the end of the thirty-second week, though they were replaced, and some failed again after some weeks. Our concern was when they failed after the replacement done in the last week of February. All the bulbs were replaced at the end of the thirty-second week.

The number of bulbs that failed per week was recorded as shown in Fig. 1.

\subsection{Model Testing}

The developed model was tested on the collected data from the field survey.

Total number of installed bulbs $=102$,

The average life span of a bulb $=32$ weeks

Cost of preventive replacement (group replacement), $C_{p}=¥ 83,400$

Cost of corrective replacement (individual replacement), $C_{f}=$ §7,950 


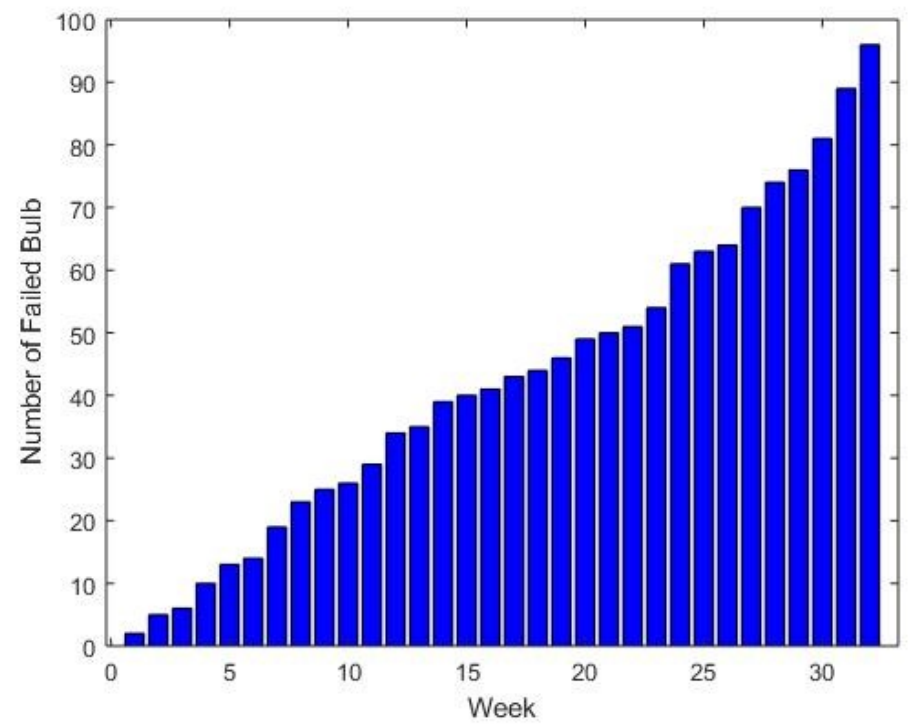

Figure 1: Cumulative number of failed bulbs per week.

Policy I: Individual Replacement Policy:

If the cost of individual replacement is cumulative, then the individual probabilities for the weeks are as shown in Table 3.

Policy 1: Group Replacement:

Figure 2 is generated from the expression

$$
F_{(t)}=N_{t} p_{t}+\sum_{x=1}^{t-1} p_{(t-x)} f_{x}
$$

This represents the cumulative total number of bulb failures in a respective week.

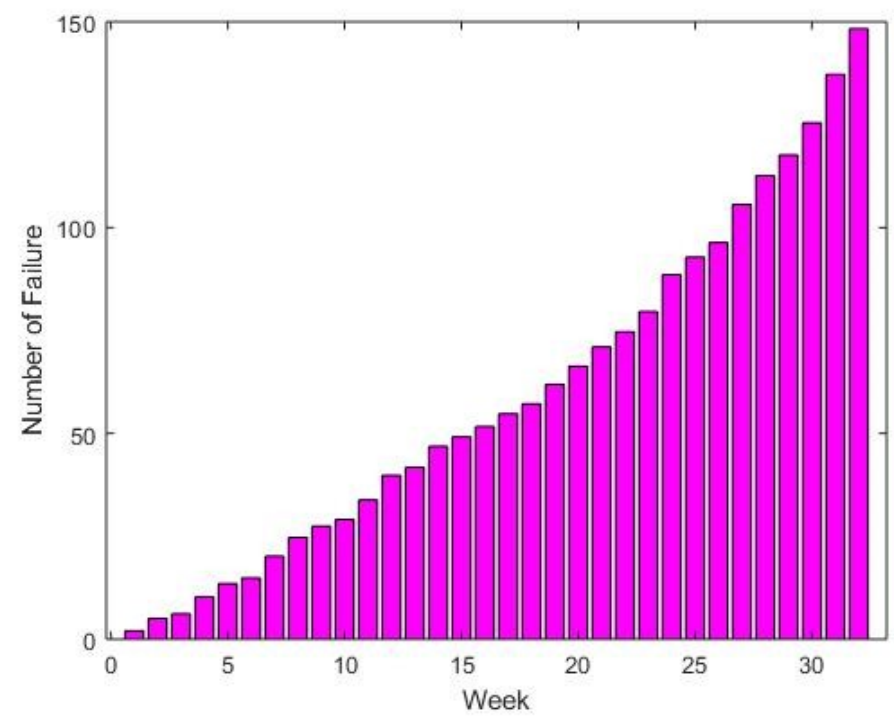

Figure 2: Cumulative total number of bulb failures in respective week.
Table 3: Computation of weekly probability of failure in a week.

\begin{tabular}{|c|c|c|c|}
\hline $\begin{array}{l}\text { Week } \\
\text { (a) }\end{array}$ & $\begin{array}{l}\text { Cumulative } \\
\text { number of } \\
\text { failed Bulb } \\
\text { per Week (b) }\end{array}$ & $\begin{array}{l}\text { Percentage } \\
\text { failure in } \\
\text { a week } c= \\
(b / 102) \times 100 \%\end{array}$ & $\begin{array}{l}\text { Weekly } \\
\text { Failure } \\
\text { Probability } \\
d=b / 102\end{array}$ \\
\hline 1 & 2 & 1.9608 & 0.0196 \\
\hline 2 & 5 & 4.9020 & 0.0490 \\
\hline 3 & 6 & 5.8824 & 0.0588 \\
\hline 4 & 10 & 9.8039 & 0.0980 \\
\hline 5 & 13 & 12.7451 & 0.1275 \\
\hline 6 & 14 & 13.7255 & 0.1373 \\
\hline 7 & 19 & 18.6275 & 0.1863 \\
\hline 8 & 23 & 22.5490 & 0.2255 \\
\hline 9 & 25 & 24.5098 & 0.2451 \\
\hline 10 & 26 & 25.4902 & 0.2549 \\
\hline 11 & 29 & 28.4314 & 0.2843 \\
\hline 12 & 34 & 33.3333 & 0.3333 \\
\hline 13 & 35 & 34.3137 & 0.3431 \\
\hline 14 & 39 & 38.2353 & 0.3824 \\
\hline 15 & 40 & 39.2157 & 0.3922 \\
\hline 16 & 41 & 40.1961 & 0.4020 \\
\hline 17 & 43 & 42.1569 & 0.4216 \\
\hline 18 & 44 & 43.1373 & 0.4314 \\
\hline 19 & 46 & 45.0980 & 0.4510 \\
\hline 20 & 49 & 48.0392 & 0.4804 \\
\hline 21 & 50 & 49.0196 & 0.4902 \\
\hline 22 & 51 & 50.0000 & 0.5000 \\
\hline 23 & 54 & 52.9412 & 0.5294 \\
\hline 24 & 61 & 59.8039 & 0.5980 \\
\hline 25 & 63 & 61.7647 & 0.6176 \\
\hline 26 & 64 & 62.7451 & 0.6275 \\
\hline 27 & 70 & 68.6275 & 0.6863 \\
\hline 28 & 74 & 72.5490 & 0.7255 \\
\hline 29 & 76 & 74.5098 & 0.7451 \\
\hline 30 & 81 & 79.4118 & 0.7941 \\
\hline 31 & 89 & 87.2549 & 0.8725 \\
\hline 32 & 96 & 94.1176 & 0.9412 \\
\hline
\end{tabular}

$$
\begin{aligned}
\text { Failure per week } & =\frac{\text { Total installed bulbs }}{\text { Mean life }} \\
& =\frac{102}{18.7866}=5.4294
\end{aligned}
$$

Individual replacement cost $=$ Individual failure per week $\times$ Cost of corrective replacement

$$
\left(C_{f}\right)=5.4294 \times 7,950=\$ 43,164 .
$$

The total cost, $C_{t}, X_{t}$, and the time of replacement is computed for group replacement.

The cost of individual replacement is $C_{f} F_{(t)}$,

Total $\operatorname{cost} C_{(t)}$ is

$$
C_{(t)}=C_{p}+C_{f} F_{(t)}
$$

The average total cost of replacement $X_{t}$ is $\left(C_{p}+\right.$ $\left.C_{f} F_{(t)}\right) \div t$.

The cost of carrying out an individual replacement as well as group replacement per week is calculated. From the result obtained, group replacement can be carried out from the fifth week as shown in Fig. 3 because the group replacement 


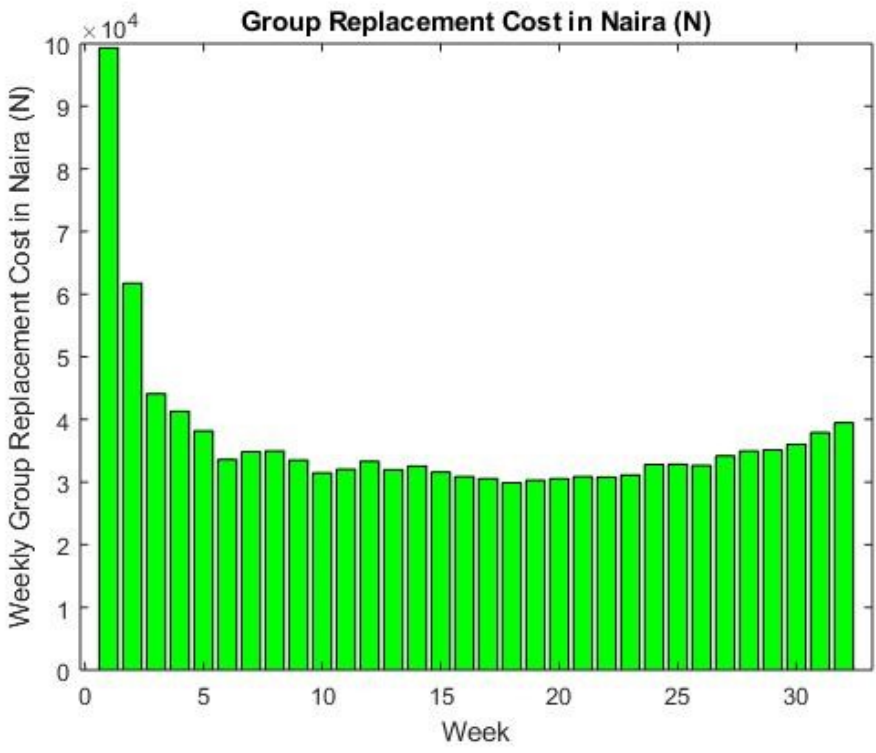

Figure 3: Weekly group replacement cost in Naira.

cost is less than the cost associated with the individual replacement of bulbs, which is 43,164 .

However, optimal group replacement will be after every eighteenth week because the average cost of replacement is at minimum at this week.

\section{RESULTS AND DISCUSSION}

The results obtained as shown in Fig. 3 indicated that the optimum time for replacement is in the eighteenth week. It would be observed that the cost of replacement is very high in the first week and started to reduce from the second week. Comparing the results obtained from Policy I (Individual Replacement Policy) and Policy II (Group Replacement Policy), it is discovered that group replacement at any time from week five to week thirty-two is cheaper than individual replacement at failure. This shows that group replacement will be a better replacement policy for stochastically failing items like bulbs. However, the optimum replacement time is in the eighteenth week. This (eighteenth-week optimum time) is exclusively for the area surveyed in this work. The optimal replacement time will be dependent on the data set used on the model. This makes the model robust for determining the optimum replacement time of any stochastically failing items once parameters like the failure rate, average life cycle, replacement costs are known.

\section{CONCLUSION}

In this work, a model has been developed to establish the optimum time for the replacement of burnt-out bulbs in street lighting system. The model can be used to establish the optimum time for the replacement of any stochastically failing item. The $(m, T)$ group replacement method was adopted to carry out this analysis. The model developed was applied to real-life data. The optimum replacement time of burnt-out streetlight bulbs was subsequently determined.
The survey conducted confirmed that the failure of bulbs is probabilistic, and all the bulbs may fail before the end of the manufacturer's specified lifetime, although some bulbs may work beyond the manufacturer's specified lifetime.

The bulb is the most failing component in a streetlight. Replacement of failed bulbs in a streetlight installation requires proper planning. Otherwise, some areas may be poorly illuminated, therefore, increasing the risks of accidents and crime. The model proposed in this work has been able to establish the optimal time for the replacement of failed bulbs. A field survey was carried out to observe the failure rate of a set of streetlights whose bulbs were all replaced with new ones the same day. The bulbs were from the manufacturer, this was to help us determine their failure rate. The failure rates of the bulbs were stochastic. The developed model, although focuses on the replacement of burnt-out bulbs in a street lighting system, it can also be used for optimal replacement decision for any stochastically failing items. Determining the optimum replacement time for failing items is of great relevance to decision-makers in the field of management. Having an optimal replacement plan enhances efficiency and increases productivity level thus resulting in overall cost reduction for facility managers.

\section{References}

[1] J. Green, C. Perkins, R. Steinbach, and P. Edwards "Reduced Street lighting at night and health: A rapid appraisal of public views in England and Wales," Health and Place, vol. 34, pp. 171-180, 2015.

[2] S. Shirsale, P. Khillare, R. Steinbach, and M. Lokhande, "Street Lights Replacement System- A Key Necessity for Make in India Campaign," International Journal of Business and Management Invention, vol. 6 , no. 1 , pp. 39-44, 2017.

[3] C. Boomsma and L. Steg, "The effect of information and values on acceptability of reduced street," Journal of Environmental Psychology, vol. 39, no. 1, pp. 22-31, 2014.

[4] G. Parise, L. Martirano, and M. Mitolo, "Electrical safety of street light systems," IEEE Transaction on Power Delivery, vol. 26, no. 3, pp. 1952-1959, 2011.

[5] M. Johansson, E. Pedersen, P. Maleetipwan-Mattsson, and T. Kuhn, "Perceived outdoor lighting quality (POLQ): A lighting assessment tool," Journal of Environmental Psychology, vol. 39, no. 1, pp. 14-21, 2014.

[6] A. Haans and Y. Kort, "Light distribution in dynamic street lighting: Two experimental studies on its effects on perceived safety, prospect, concealment, and escape," Journal of Environmental Psychology, vol. 32, no. 4, pp. $342-352,2012$.

[7] A. Murray and X. Feng, "Public street lighting service standard assessment and achievement," SocioEconomic Planning Sciences, vol. 53, no. 1, pp. 14-22, 2016.

[8] J. Asalor and I. W. Ujevwerume, "Assessment of availability of street light system: A study of Warri, Delta State, Nigeria," Nigerian Journal of Technology, vol. 39, no. 2, pp. 536-541, 2020.

[9] D. Preston and K. Ujevwerume, "Cost-benefit analysis of retrofit of high-intensity," Energy Efficiency, vol. 6 , no. 1 , pp. $255-269,2013$.

[10] A. Dale, M. Bilec, J. Marriott, D. Hartley, C. Jurgens, and E. Zatcoff, "Cost-benefit analysis of retrofit of highintensity," Journal of Infrastructure Systems, vol. 17, no. 4, pp. 192-199, 2011 .

[11] T. Leena and H. Liisa, "Life cycle assessment of road lighting luminaires-comparison of light-emitting diode 
and high-pressure sodium technologies," Journal of Clearner Production, vol. 93, pp. 234-242, 2015.

[12] K. Ochs, M. Miller, and A. Thal, "Time valued technology: Evaluating infrastructure replacement with rapidly emerging technology," in IIE Annual Conference Proceedings, 2012.

[13] A. Sabina, A. Muna, A. Meshayel, and A. Hassan, "Comparative Life Cycle Assessment (LCA) of streetlight technologies for minor roads in United Arab Emirates," Energy for Sustainable Development, vol. 17, no. 5, pp. 438-450, 2013.

[14] A. Ozadowicz and J. Grela, "Energy saving in the street lighting control system-A new approach based on the EN-15232 standard," Energy Efficiency, vol. 10, no. 3, pp. 563-576, 2017.

[15] O. Mohammed, A. Otuoze, S. Salisu, A. Abioye, A. Usman, and R. Alao, "The challenges and panaceas to power distribution losses in Nigeria," Arid Zone Journal of Engineering, Technology and Environment, vol. 16 , no. 1 , pp. $120-136,2020$.

[16] World-Bank. (2018, November) World bank. [Online]. Available: https://data.worldbank.org/indicator/ SP.POP.TOTL

[17] Fpwh. (2018, November) Federal Ministry of Power, Works and Housing. [Online]. Available: http://www. pwh.gov.ng/index

[18] R. Bilam, A. Aditya, K. Tanmoy, K. Sudip, and D. Jayita, "A smart street-light intensity optimizer," in 2018 Emerging Trends in Electronic Devices and Computational Techniques, Kolkata, India, 2018.

[19] S. Lau, G. Merrett, and N. White, "Energy-efficient street lighting through embedded adaptive intelligence," in 2013 International Conference on Advanced Logistics and Transport, Sousse, Tunisia, 2013.

[20] H. Lee and J. Cha, "New stochastic models for preventive maintenance and maintenance optimization," European Journal of Operational Research, vol. 255, no. 1 , pp. 80-90, 2016.

[21] A. Chelbi and D. Ait-Kadi, "Analysis of a production/inventory system with randomly faily production unit submitted to regular preventive maintenance," $E u$ ropean Journal of Operational Research, vol. 156, no. 1, pp. 712-718, 2004.

[22] G. Denardin, C. Barriquello, A. Campos, R. Pinto, M. Dalla-Costa, and R. do Prado, "Control network for modern street lighting systems," in 2011 IEEE International Symposium on Industrial Electronics, 2011.

[23] M. Bezbradica and Z. Trpovski, "Advanced street lighting maintenance using gps, light intensity measuring and incremental cost-effectiveness ratio," in 2014 International Conference on High Performance Computing \& Simulation (HPCS), 2014.

[24] C. Galatanu, C. Haba, D. Petrișor, and L. Breniuc, "Imaging measurements for public lighting predictive maintenance," in 2019 11th International Symposium on Advanced Topics in Electrical Engineering (ATEE), 2019.

[25] G. Liu, "M-failure group replacement model for queueing systems with unreliable and repairable servers," Journal of the Chinese Institute of Industrial Engineers, vol. 21 , no. 5 , pp. 423-431, 2004.

[26] L. Thomas, "A survey of maintenance and replacement models for maintainability and reliability of multi-item systems," Reliability Engineering, vol. 16, no. 4, pp. 297-309, 1986.

[27] D. Godoy, P. Knights, and R. Pascual, "Value-based optimisation of replacement intervals for critical spare components," International Journal of Mining, Reclamation and Environment, vol. 32, no. 4, pp. 264-272, 2018. 